Seyedeh Sara HOSSEINI, PhD Candidate

E-mail:s.hosseini794@gmail.com

Department of Mathematics, Islamic Azad University

Qazvin Branch, Qazvin, Iran

Associate Professor Reza Kazemi MATIN, PhD

E-mail: rkmatin@kiau.ac.ir (Corresponding author)

Department of Mathematics, Islamic Azad University

Karaj Branch, Karaj, Iran

Assistant Professor Zohreh MOGHADAS, PhD

E-mail: Zmoghaddas@qiau.ac.ir

Department of Mathematics, Islamic Azad University

Qazvin Branch, Qazvin, Iran

Assistant Professor Mohsen KHUNSIAVASH, PhD

E-mail: mfsiavash@gmail.com

Department of Mathematics, Islamic Azad University

Qazvin Branch, Qazvin, Iran

\title{
NON-PARAMETRIC METHODS FOR PRODUCTIVITY ANALYSIS OF SERIES NETWORK PRODUCTION SYSTEMS WITH STOCHASTIC DATA
}

\begin{abstract}
Data envelopment analysis (DEA) is a mathematically-based programming method widely used for the performance assessment of Decision Making Units (DMUs). In recent years, to investigate the productivity changes between two time periods, Malmquist productivity index (MPI) has been extensively utilized. The novelty of the present research is considering MPI of series structural network with stochastic data in order to investigate the progress or regress of the system as well as each sub-process, the identification of which leads the performance of the system to improve or decline. The important feature of this study is introducing a new chanceconstrained network DEA model with stochastic data and then converting it into quadratic programming equivalent model for MPI evaluation. Finally, two numerical examples are provided as illustration.

Keywords: Data envelopment analysis (DEA),Malmquist productivity index (MPI),Series network model, Chance constrained programming approach.
\end{abstract}

JEL Classification: C61, D24 
Seyedeh S. Hosseini, Reza K. Matin, Zohreh Moghadas, Mohsen Khunsiavash

\section{Introduction}

Data envelopment analysis (DEA) is an appropriate instrument based on a mathematical programming method for performance and productivity evaluation of homogenous production processes. Its origin dates back to the article written by Farrell (1957), which has current popularity due to the paper provided by Charnes et al. (1987), utilized to evaluate the performance of Decision-making Units (DMUs).

Productivity changes are some of the theoretical issues in production economy that have long been discussed in the literature. As an important technique to measure productivity in two various time intervals in production periods, we can refer to the Malmquist productivity index (MPI). Malmquist index has been widely used in production economics. In their study, Cooper et al. (2004) analyzed the Malmquist productivity index in terms of distance functions with panel data. For the empirical application of MPI, we can refer to Maniadakis et al. (2004), Yao et al. (2016), and Aparicio et al. (2017) among others.

In applying DEA as a non-parametric technique for performance evaluation of DMUs, a basic assumption is that inputs and outputs data are assumed to be known and deterministic; see Charnes et al. (1987) as an example. This may cause some restrictions in applying DEA in practice since in many real world applications of performance measurement such as banks, supply chain operations, and finance, the inputs/outputs data are often stochastic. So, using stochastic data instead of deterministic data allows us to present models that are more reliable to be adjusted to the real environment. This concept in the conventional DEA literature is referred to as stochastic data envelopment analysis. The conventional DEA models for calculating performance and determining the regress and progress of performance with stochastic data require adjustment.

There exist two main different approaches in dealing with uncertainty in production economics. One is based on applying Stochastic Frontier Analysis (SFA) and the other is applying chance-constrained DEA technique. Kuosmanen (2006) tried to combine both techniques in a single framework that is called Stochastic Non Parametric Data (StoNED). There is a considerable number of studies in dealing with DEA estimation of production processes. See, for example, HosseinzadehLotfi et al. (2001), Cooper et al. (2004), Khodabakhshi (2012), and Ross et al. (2016) pointed out that issues of applying stochastic data is DEA framework are studied by using the chance-constrained approach.

In addition to the issue of dealing with stochastic data, the complexity of the conditions of the production process is one of the other challenges that researchers confront. In reality, production process is more than a simple transformation of inputs to outputs as is assumed in traditional DEA models. It is more likely to have internal 
Non-Parametric Methods for Productivity Analysis of Series Network Production Systems With Stochastic Data

sub-processes in dealing with performance measurement of production units. In recent DEA literature, numerous studies have been conducted to consider these issues under the title of network DEA. In some of these studies, it has been assumed that production systems are composed of two steps; see for example Chen (2004) among others. Färe and Grosskopf (2000) proposed a method for the analysis of the performance of each sub-process, taking intermediate products into account. Kao and Hwang (2008) introduced a model under the assumption of series structures between stages. Kao (2009) also developed a model with parallel structures in the production processes as well as a methodology for evaluating systems with the general structure. Besides, Kao and Hwang (2010) presented a model to demonstrate the relative relationship between the system performance and its sub-processes. Further, Lozano (2011) proposed a comprehensive model for systems with network structures and discussed the costs and efficiency of the scale. Moreover, Kao (2014) presented a general SBM model to evaluate the efficiency of network systems broken down into the weighted mean of the process efficiency. More recently, Kazemi Matin and Azizi (2015) introduced a radial and a multiple approach to modeling network systems with a general structure. In the meantime, however, some researchers addressed the productivity of network systems. For example, Kao (2017) introduced network DEA model to calculate the Malmquist productivity index of a network system in which the relationship between the system and Malmquist productivity index helps to identify the process that introduces amendments to the system for future planning.

According to the above mentioned studies in the network DEA field and to the best of our knowledge, little attention has been paid to evaluating the regress and progress of network models in the presence of stochastic data.

In this study, we aim to develop a novel DEA approach for dealing with regress and progress status of network production systems with series structure in the presence of stochastic data. An important challenge in this way is the computational complexities of conventional DEA models after applying the stochastic data. Based on the chance-programming technique, the introduced optimization models to calculate efficiency scores of the observed DMUs are then transformed into equivalent models with quadratic constraints which are easy to solve. In the new approach provided in this study, we need to assume that inputs, intermediate, and output data are stochastic variables with normal distribution. The results of the new models are easy to apply and interpret in real world applications.

The remainder of this study is organized as follow. In the next Section, a brief introduction to the Malmquist productivity index as well as the standard network DEA for series structures is presented. Section 3 is devoted to the new approach for estimating Malmquist index for series production systems with stochastic data. In

DOI: $10.24818 / 18423264 / 53.2 .19 .10$ 
Seyedeh S. Hosseini, Reza K. Matin, Zohreh Moghadas, Mohsen Khunsiavash

Section 4, two numerical examples are used to explain the presented method. Section 5 concludes the paper.

\section{Malmquist index for a production system with series structure}

The analysis of productivity is one of the important theoretical issues in production economy, which has been attracted the attention of researchers in DEA framework. In this respect, the Malmquist productivity index is of major importance when considered as an instrument for evaluating productivity in two time periods. In network DEA models, a production system is typically composed of several sub-processes and applying Malmquist productivity index helps to measure regress or progress status in the performance of production systems. However, it is possible that when the performance of a production system is improved in time periods, some sub-processes may perform worse; the opposite is also true. Therefore, it is of significant importance to find out a relationship between Malmquist productivity index of the system and its sub-process. Kao (2016) has pointed to this issue in DEA framework. With regard to the fact that Malmquist productivity index is the ratio of two efficiencies in period $t$ and $t+1$, the relationship between Malmquist productivity index of system and subprocesses will be figured out based on these items.

Following Kao (2014), suppose that there exist $\mathrm{n}$ observed DMUs consisting of $q$ subprocesses and each $D M U_{j}(j=1, \ldots, n)$ consumes $m$ inputs $x_{i j}(i=1, \ldots, m)$ to produce $d$ intermediate produces denoted by $z_{d j}(d=1, \ldots, D)$ which are also utilized as the inputs of the preceding stage. Notations $x_{i j}{ }^{p}$ and $y_{i j}{ }^{p}$ for all $i, r$ and $j$ indicate the inputs and outputs in the $p$ th process, respectively. Also, suppose that the index $l$ represents time periods $\mathrm{t}$ and $\mathrm{t}+1$. To calculate the $k$ th unit's efficiency score, we have the following linear programming model; Kao (2014):

$$
\begin{aligned}
\left(E_{k}{ }^{S}\right)=\max & \sum_{r=1}^{s} u_{r} y_{r k} \\
\text { s.t } \quad & \sum_{i=1}^{m} v_{i} x_{i k}=1, \\
& \sum_{d=1}^{D} w_{d}^{1} z_{d j}^{1}-\sum_{i=1}^{m} v_{i} x_{i j} \leq 0, \quad j=1, \ldots, n, \\
& \sum_{d=1}^{D} w_{d}^{p} z_{d j}^{p}-\sum_{d=1}^{D} w_{d}^{p-1} z_{d j}^{p-1} \leq 0, \quad p=2, \ldots, q-1, \\
& \sum_{r=1}^{s} u_{r} y_{r j}-\sum_{d=1}^{D} w_{d}^{q-1} z_{d j}^{q-1} \leq 0, \quad j=1, \ldots, n, \quad i=1, \ldots, m, \\
& u_{r} \geq 0, v_{i} \geq 0, w_{d}^{p} \geq 0, \quad r=1, \ldots, s, \quad d=1, \ldots, D, \quad p=1, \ldots, q .
\end{aligned}
$$

The dual (envelopment form) of the above series (multiplier) model under constant returns to scale (CRS) assumption takes the following form which is more useful in 
Non-Parametric Methods for Productivity Analysis of Series Network Production Systems With Stochastic Data

applying chance-constrained technique for MPI evaluation with stochastic data.

$$
\begin{aligned}
\left(E_{k}\right)^{s}= & \min \theta \\
\text { s.t } \quad & \sum_{j=1}^{n} \lambda_{j}^{p} x_{i j}^{p} \leq \theta x_{i k}^{p}, \quad i=1, \ldots, m, \quad p=1, \ldots, q, \\
& \sum_{j=1}^{n} \lambda_{j}^{p} z_{d j}^{p} \geq z_{d k}^{p}, \quad d=1, \ldots, \mathrm{D}, \quad p=1, \ldots, q-1, \\
& \sum_{j=1}^{n} \lambda_{j}^{p+1} z_{d j}^{p} \leq z_{d k}^{p}, d=1, \ldots, \mathrm{D}, \quad p=1, \ldots, q-1, \\
& \sum_{j=1}^{n} \lambda_{j}^{p} y_{r j}^{p} \geq y_{r k}^{p}, \quad r=1, \ldots, \mathrm{s}, \quad p=1, \ldots, q, \\
& \lambda_{j}^{p} \geq 0, \\
& j=1, \ldots, \mathrm{n}, \quad p=1, \ldots, q .
\end{aligned}
$$

Kao and Hwang (2011) and (2014) demonstrated that the MPI for the system when the $k$ th unit is under assessment, $M_{k}^{S}$, is defined based on the ratio of efficiency of period $\mathrm{t}+1,\left(E_{k}{ }^{S}\right)^{t+1}$, to the efficiency of period $\mathrm{t},\left(E_{k}{ }^{S}\right)^{t}$. So, to calculate MPI of a series system, we need to calculate the proportion of efficiency in period $t+1$ to that of in period t. An MPI value less than one indicates the regress of efficiency and in the case that it is greater than 1, it signifies the progress of efficiency and if the value equals 1 the system makes neither a progress nor a regress, see Kao (2016) for more detail.

\section{The Malmquist productivity index for production systems with series structures and stochastic data}

In most conventional DEA models, the input and output data are assumed to be deterministic. Similarly, if the system has operated in different periods, both data of one period or a combination of data of several periods have been used as a set of deterministic data. Kao (2016) and (2017) introduced network DEA models in order to calculate the MPI and evaluate the regress or progress of production systems. According to their review of network DEA literature and to the best of our knowledge, most of the current DEA models in dealing with MPI are based on deterministic data. In this section, we address this issue by investigating the conditions under which we can use stochastic data in productivity evaluation of the production system with series structure.

To do so, we employed the chance-constrained programming technique which allows us to compute the stochastic inputs and outputs and produce more desirable real results. Let's consider the stochastic input, intermediate products, and outputs for each unit in periods $t$ and $t+1$ as the following random valued vector:

DOI: $10.24818 / 18423264 / 53.2 .19 .10$ 
Seyedeh S. Hosseini, Reza K. Matin, Zohreh Moghadas, Mohsen Khunsiavash

$\begin{array}{lll}\tilde{\boldsymbol{x}}_{j}^{t+1}=\left(\tilde{x}_{1 j}^{t+1}, \ldots, \tilde{x}_{m j}^{t+1}\right), & \tilde{\mathbf{z}}_{j}^{t+1}=\left(\tilde{z}_{1 j}^{t+1}, \ldots, \tilde{z}_{d j}^{t+1}\right), & \tilde{\boldsymbol{y}}_{j}^{t+1}=\left(\tilde{y}_{1 j}^{t+1}, \ldots, y_{s j}^{t+1}\right), \\ \tilde{\boldsymbol{x}}_{j}^{t}=\left(\tilde{x}_{1 j}^{t}, \ldots, \tilde{x}_{m j}^{t}\right), & \tilde{\mathbf{z}}_{j}^{t}=\left(\tilde{z}_{1 j}^{t}, \ldots, \tilde{z}_{d j}^{t}\right), & \widetilde{\boldsymbol{y}}_{j}^{t}=\left(\tilde{y}_{1 j}^{t}, \ldots, y_{s j}^{t}\right) .\end{array}$

To calculate MPI for series production systems with stochastic data, we need to compute the following ratio of the efficiencies:

$$
\tilde{M}_{k}^{S}=\frac{\left(\tilde{E}_{k}^{S}\right)^{t+1}}{\left(\tilde{E}_{k}^{S}\right)^{t}}=\frac{\prod_{p=1}^{q}\left(\tilde{E}_{k}^{p}\right)^{t+1}}{\prod_{p=1}^{q}\left(\tilde{E}_{k}^{p}\right)^{t}}=\prod_{p=1}^{q} \frac{\left(\tilde{E}_{k}^{p}\right)^{t+1}}{\left(\tilde{E}_{k}^{p}\right)^{t}}=\prod_{p=1}^{q} \tilde{M}_{k}^{p} .
$$

The value of $\tilde{M}_{k}^{S}$ indicates the stochastic MPI. To provide the required items in (4), the following chance-constrained version of the model (2) needs to be solved. Here, $\operatorname{Pr}$ indicates "probability" and " $\sim$ " presents the data as random variables with a normal distribution and $\alpha \in(0,1]$ indicates a predefined and reasonable minute size of a type one error, i.e., an allowable chance of failing to satisfy the constraints. Note that $l \in\{t, t+1\}$ is used to indicate two time periods.

$$
\begin{aligned}
\left(\tilde{E}_{k}{ }^{s}\right)^{l}= & \min \theta \\
\text { s. } \quad & P\left\{\sum_{j=1}^{n} \lambda_{j}^{p}\left(x_{i j}^{p}\right)^{l} \leq \theta\left(x_{i k}^{p}\right)^{l}\right\} \geq 1-\alpha, \quad i=1, \ldots, m, \quad p=1, \ldots, q, \\
& P\left\{\sum_{j=1}^{n} \lambda_{j}^{p}\left(z_{d j}^{p}\right)^{l} \geq\left(z_{d k}^{p}\right)^{l}\right\} \geq 1-\alpha, \quad d=1, \ldots, \mathrm{D}, \quad p=1, \ldots, q-1, \\
& P\left\{\sum_{j=1}^{n} \lambda_{j}^{p+1}\left(z_{d j}^{p}\right)^{l} \leq\left(z_{d k}^{p}\right)^{l}\right\} \geq 1-\alpha, \quad d=1, \ldots, \mathrm{D}, \quad p=1, \ldots, q-1, \\
& P\left\{\sum_{j=1}^{n} \lambda_{j}^{p}\left(y_{r j}^{p}\right)^{l} \geq\left(y_{r k}^{p}\right)^{l}\right\} \geq 1-\alpha, \quad r=1, \ldots, \mathrm{s}, \quad p=1, \ldots, q, \\
& \lambda_{j}^{p} \geq 0, \quad j=1, \ldots, \mathrm{n}, \quad p=1, \ldots, q .
\end{aligned}
$$

To convert the chance-constrained optimization Model (5) to a deterministic equivalent version, we can proceed as follows. The first constraint of Model (5) can be stated as follows:

$$
\operatorname{Pr}\left\{\sum_{j=1}^{n} \lambda_{j}^{p}\left(\tilde{x}_{i j}^{p}\right)^{l}-\theta\left(\tilde{x}_{i k}^{p}\right)^{l} \leq 0\right\} \geq 1-\alpha, \quad i=1, . ., \mathrm{m},
$$


Non-Parametric Methods for Productivity Analysis of Series Network Production Systems With Stochastic Data

Accordingly, by using the definition of the expected value and variance of the elements, we may write the above equation as follows:

$$
\operatorname{Pr}\left[\frac{\sum_{j=1}^{n} \lambda_{j}^{p}\left(\tilde{x}_{i j}^{p}\right)^{l}-\theta\left(\tilde{x}_{i k}^{p}\right)^{l}-E\left(\sum_{j=1}^{n} \lambda_{j}^{p}\left(\tilde{x}_{i j}^{p}\right)^{l}-\theta\left(\tilde{x}_{i k}^{p}\right)^{l}\right)}{\sqrt{\operatorname{var}\left(\sum_{j=1}^{n} \lambda_{j}^{p}\left(\tilde{x}_{i j}^{p}\right)^{l}-\theta\left(\tilde{x}_{i k}^{p}\right)^{l}\right)}} \leq \frac{0-E\left(\sum_{j=1}^{n} \lambda_{j}^{p}\left(\tilde{x}_{i j}^{p}\right)^{l}-\theta\left(\tilde{x}_{i k}^{p}\right)^{l}\right)}{\sqrt{\operatorname{var}\left(\sum_{j=1}^{n} \lambda_{j}^{p}\left(\tilde{x}_{i j}^{p}\right)^{l}-\theta\left(\tilde{x}_{i k}^{p}\right)^{l}\right)}}\right] \geq 1-\alpha
$$

For the sake of simplicity let $\sqrt{\operatorname{var}\left(\sum_{j=1}^{n} \lambda_{j}^{p}\left(\tilde{x}_{i j}^{p}\right)^{l}-\theta\left(\tilde{x}_{i k}^{p}\right)^{l}\right)}$ denoted by $\sigma_{i}(\theta, \lambda)$. Therefore, we may write

$$
\operatorname{Pr}\left[\frac{\sum_{j=1}^{n} \lambda_{j}^{p}\left(\tilde{x}_{i j}^{p}\right)^{l}-\theta\left(\tilde{x}_{i k}^{p}\right)^{l}-\sum_{j=1}^{n} \lambda_{j}^{p}\left(\tilde{x}_{i j}^{p}\right)^{l}+\theta\left(\tilde{x}_{i k}^{p}\right)^{l}}{\sigma_{i}(\theta, \lambda)} \leq \frac{0-\sum_{j=1}^{n} \lambda_{j}^{p}\left(\tilde{x}_{i j}^{p}\right)^{l}+\theta\left(\tilde{x}_{i k}^{p}\right)^{l}}{\sigma_{i}(\theta, \lambda)}\right] \geq 1-\alpha \text {. If we denote the left- }
$$

hand side of the above inequality by $z_{j}$, it follows a normal standard distribution with zero mean and unit variance. Hence, we can write:

$$
\operatorname{Pr}\left[z_{j} \leq \frac{0-\sum_{j=1}^{n} \lambda_{j}^{p}\left(x_{i j}^{p}\right)^{l}+\theta\left(x_{i k}^{p}\right)^{l}}{\sigma_{i}(\theta, \lambda)}\right] \geq 1-\alpha \text { thus we have: } \Phi\left[\frac{-\sum_{j=1}^{n} \lambda_{j}^{p}\left(x_{i j}^{p}\right)^{l}+\theta\left(x_{i k}^{p}\right)^{l}}{\sigma_{i}(\theta, \lambda)}\right] \geq 1-\alpha \text { where } \Phi
$$

represent the normal cumulative distribution function. So, taking the inverse $\Phi^{-1}$, we obtain $\frac{-\sum_{j=1}^{n} \lambda_{j}^{p}\left(x_{i j}^{p}\right)^{l}+\theta\left(x_{i k}^{p}\right)^{l}}{\sigma_{i}(\theta, \lambda)} \geq \Phi^{-1}(1-\alpha)$. Finally, the first constraint of Model (5) is converted to the following deterministic equivalent:

$\sum_{j=1}^{n} \lambda_{j}^{p}\left(x_{i j}^{p}\right)^{l}-\Phi^{-1}(\alpha) \sigma_{i}(\theta, \lambda) \leq \theta\left(x_{i k}^{p}\right)^{l}, \quad i=1, \ldots, \mathrm{m}, \mathrm{p}=1, \ldots \mathrm{q}$.

The same argument could be provided for the other constraints. The choice of multivariate normal distributions and zero-order rules are less restrictive than might at 
Seyedeh S. Hosseini, Reza K. Matin, Zohreh Moghadas, Mohsen Khunsiavash

first appears to be. Transformations are available for converting other types of distributions into approximately normal form (Cooper et al., 2004).

To calculate $\left(\sigma_{i}(\theta, \lambda)\right)^{2}$, we can write

$$
\begin{aligned}
& \operatorname{var}\left(\sum_{j=1}^{n} \lambda_{j}^{p}\left(\tilde{x}_{i j}^{p}\right)^{l}-\theta\left(\tilde{x}_{i k}^{p}\right)^{l}\right)=\operatorname{var}\left(\sum_{\substack{j=1 \\
j \neq k}}^{n} \lambda_{j}^{p}\left(\tilde{x}_{i j}^{p}\right)^{l}+\left(\lambda_{j}^{p}-\theta\right)\left(\tilde{x}_{i k}^{p}\right)^{l}\right) \\
& =\operatorname{var}\left(\sum_{\substack{j=1 \\
j \neq k}}^{n} \lambda_{j}^{p}\left(\tilde{x}_{i j}^{p}\right)^{l}\right)+\operatorname{var}\left(\left(\lambda_{j}^{p}-\theta\right)\left(\tilde{x}_{i k}^{p}\right)^{l}\right)+2 \operatorname{Cov}\left(\sum_{\substack{j=1 \\
j \neq k}}^{n} \lambda_{j}^{p}\left(\tilde{x}_{i j}^{p}\right)^{l},\left(\lambda_{j}^{p}-\theta\right)\left(\tilde{x}_{i k}^{p}\right)^{l}\right), \quad i=1, \ldots \mathrm{m} .
\end{aligned}
$$

Therefore,

$$
\begin{aligned}
& \left(\sigma_{i}(\theta, \lambda)\right)^{2}=\sum_{\substack{j=1 \\
j \neq k}}^{n}\left(\left(\lambda_{j}^{p}\right)^{2} \operatorname{Var}\left(\tilde{x}_{i j}^{p}\right)^{l}\right)+\sum_{o \neq k} \sum_{j \neq k} \lambda_{o}^{p} \lambda_{j}^{p} \operatorname{Cov}\left(\tilde{x}_{i o}^{p}, \tilde{x}_{i j}^{p}\right)+2\left(\lambda_{k}^{p}-\theta\right) \sum_{o \neq k} \lambda_{k}^{p} \operatorname{Cov}\left(\tilde{x}_{i o}^{p}, \tilde{x}_{i k}^{p}\right) \\
& +\left(\lambda_{k}^{p}-\theta\right)^{2} \operatorname{Var}\left(\tilde{x}_{i k}^{p}\right)^{l}, \quad i=1, \ldots, \mathrm{m} .
\end{aligned}
$$

\section{Illustrative examples}

In this section, two numerical example are provided to illustrate the results of the proposed approach. The results in both cases are used to evaluate and demonstrate the regress and progress of the associated production system.

\subsection{Example 1. A two-stage network production case}

To explain this method, we consider the average data set in Table 1 for 8 DMUs in two time periods $t$ and $t+1$ that are composed of three inputs, three outputs, and four

\begin{tabular}{|c|c|c|c|c|c|c|c|c|c|c|c|c|c|c|c|c|c|}
\hline \multicolumn{9}{|c|}{ Time period $t$} & \multicolumn{9}{|c|}{ Time period $t+1$} \\
\hline DMUs & 1 & 2 & 3 & 4 & 5 & 6 & 7 & 8 & DMUs & 1 & 2 & 3 & 4 & 5 & 6 & 7 & 8 \\
\hline $\mathrm{X} 1$ & 2 & 3 & 3 & 4 & 5 & 5 & 5 & 6 & $\mathrm{X} 1$ & 2 & 2 & 4 & 3 & 4 & 5 & 6 & 5 \\
\hline $\mathrm{X} 2$ & 4 & 5 & 6 & 6 & 6 & 7 & 8 & 9 & $\mathrm{X} 2$ & 4 & 5 & 7 & 5 & 5 & 7 & 7 & 8 \\
\hline $\mathrm{X} 3$ & 3 & 3 & 3 & 4 & 4 & 5 & 5 & 5 & X3 & 2 & 4 & 4 & 3 & 4 & 6 & 5 & 4 \\
\hline $\mathrm{Z1}$ & 2 & 3 & 2 & 3 & 4 & 4 & 4 & 5 & $\mathrm{Z1}$ & 3 & 3 & 3 & 3 & 4 & 4 & 4 & 5 \\
\hline $\mathrm{Z} 2$ & 2 & 3 & 2 & 3 & 3 & 3 & 4 & 4 & $\mathrm{Z} 2$ & 2 & 3 & 4 & 3 & 3 & 4 & 5 & 5 \\
\hline $\mathrm{Z} 3$ & 3 & 2 & 4 & 4 & 3 & 4 & 5 & 4 & $\mathrm{Z3}$ & 3 & 2 & 4 & 4 & 3 & 5 & 5 & 4 \\
\hline $\mathrm{Z4}$ & 3 & 3 & 4 & 3 & 4 & 5 & 5 & 5 & Z4 & 3 & 4 & 4 & 3 & 3 & 5 & 4 & 4 \\
\hline Y1 & 5 & 5 & 6 & 7 & 7 & 8 & 9 & 9 & Y1 & 6 & 5 & 7 & 7 & 7 & 9 & 9 & 9 \\
\hline
\end{tabular}
intermediate products as depicted in Figure 1. It is also assumed that the data are normally distributed and have specific standard deviations in the interval $(0.1,0.7)$.

Table 1:Random average data in period's $t$ and $t+1$ for example 1 . 
Non-Parametric Methods for Productivity Analysis of Series Network Production Systems With Stochastic Data

\begin{tabular}{l|llllllll|l|llllllll}
$\mathrm{Y} 2$ & 5 & 6 & 6 & 6 & 7 & 8 & 9 & 9 & $\mathrm{Y} 2$ & 5 & 7 & 8 & 6 & 6 & 9 & 9 & 9 \\
$\mathrm{Y} 3$ & 4 & 5 & 5 & 7 & 7 & 8 & 9 & 8 & $\mathrm{Y} 3$ & 4 & 6 & 7 & 6 & 7 & 9 & 9 & 9 \\
\hline
\end{tabular}

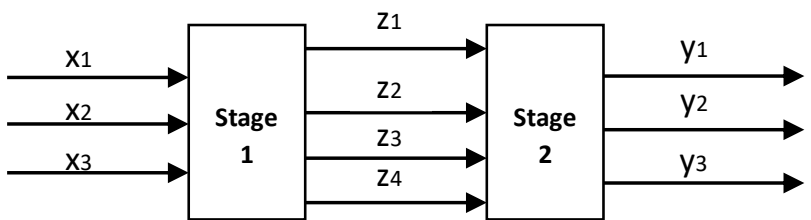

Figure 1: Network structure of the two-stage series network for example1.

The associated deterministic and chance-constrained versions of Models (5) for this two-stage series network could be stated as follows:

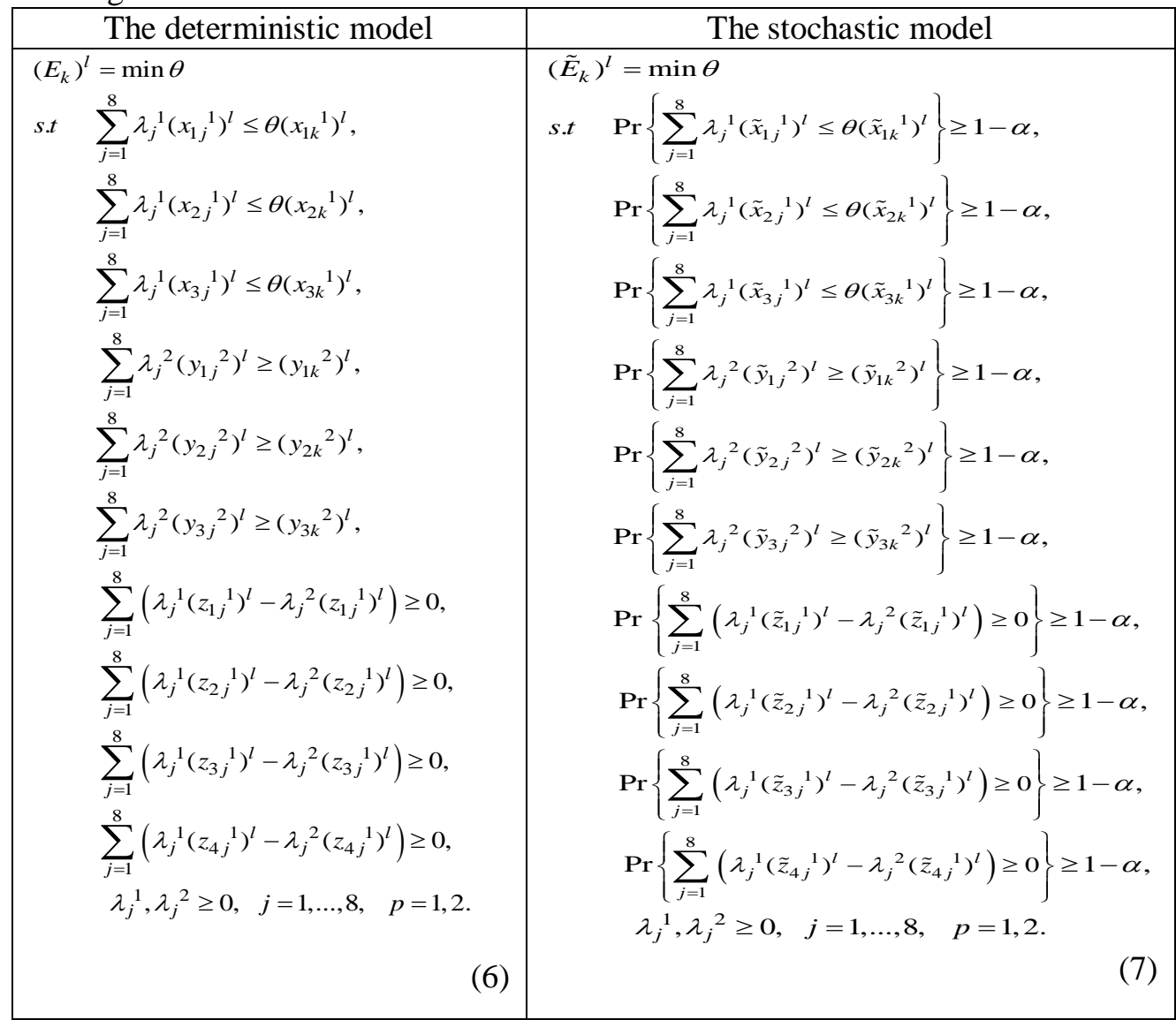


Seyedeh S. Hosseini, Reza K. Matin, Zohreh Moghadas, Mohsen Khunsiavash

Now, based on the provided details, it is possible to re-write Model (7) in its corresponding deterministic equivalent model as follows:

$$
\begin{aligned}
& \left(E_{k}\right)^{l}=\min \theta \\
& \text { s.t } \quad \sum_{j=1}^{8} \lambda_{j}{ }^{1}\left(x_{1 j}{ }^{1}\right)^{l}-\Phi^{-1}(\alpha)\left(\omega_{1}^{I}\right)^{l} \leq \theta\left(x_{1 k}{ }^{1}\right)^{l} \text {, } \\
& \sum_{j=1}^{8} \lambda_{j}{ }^{1}\left(x_{2 j}{ }^{1}\right)^{l}-\Phi^{-1}(\alpha)\left(\omega_{2}^{I}\right)^{l} \leq \theta\left(x_{2 k}{ }^{1}\right)^{l}, \\
& \sum_{j=1}^{8} \lambda_{j}{ }^{1}\left(x_{3 j}{ }^{1}\right)^{l}-\Phi^{-1}(\alpha)\left(\omega_{3}^{I}\right) \leq \theta\left(x_{3 k}{ }^{1}\right)^{l}, \\
& \sum_{j=1}^{8} \lambda_{j}{ }^{2}\left(y_{1 j}{ }^{2}\right)^{l}+\Phi^{-1}(\alpha)\left(\omega_{1}^{O}\right)^{l} \geq\left(y_{1 k}{ }^{2}\right)^{l}, \\
& \sum_{j=1}^{8} \lambda_{j}{ }^{2}\left(y_{2 j}{ }^{2}\right)^{l}+\Phi^{-1}(\alpha)\left(\omega_{2}^{O}\right)^{l} \geq\left(y_{2 k}{ }^{2}\right)^{l}, \\
& \sum_{j=1}^{8} \lambda_{j}{ }^{2}\left(y_{3 j}{ }^{2}\right)^{l}+\Phi^{-1}(\alpha)\left(\omega_{3}^{O}\right)^{l} \geq\left(y_{3 k}{ }^{2}\right) l, \\
& \sum_{j=1}^{8}\left(\lambda_{j}{ }^{1}\left(z_{1 j}{ }^{1}{ }^{l}-\lambda_{j}{ }^{2}\left(z_{1 j}{ }^{1}\right)^{l}\right)+\Phi^{-1}(\alpha)\left(\omega_{1}^{D}\right)^{l} \geq 0,\right. \\
& \sum_{j=1}^{8}\left(\lambda_{j}{ }^{1}\left(z_{2, j}{ }^{1}\right)^{l}-\lambda_{j}{ }^{2}\left(z_{2, j}{ }^{1}\right)^{l}\right)+\Phi^{-1}(\alpha)\left(\omega_{2}^{D}\right)^{l} \geq 0, \\
& \sum_{j=1}^{8}\left(\lambda_{j}{ }^{1}\left(z_{3, j}{ }^{1}\right)^{l}-\lambda_{j}{ }^{2}\left(z_{3 j}{ }^{1}{ }^{l}\right)+\Phi^{-1}(\alpha)\left(\omega_{3}^{D}\right)^{l} \geq 0,\right. \\
& \sum_{j=1}^{8}\left(\lambda_{j}{ }^{1}\left(z_{4 j}{ }^{1}\right)^{l}-\lambda_{j}{ }^{2}\left(z_{4 j}{ }^{1}\right)^{l}\right)+\Phi^{-1}(\alpha)\left(\omega_{4}^{D}\right)^{l} \geq 0, \\
& \lambda_{j}{ }^{1}, \lambda_{j}{ }^{2} \geq 0, \quad j=1, \ldots, 8 .
\end{aligned}
$$

Where $l \in\{\mathrm{t}, \mathrm{t}+1\}$ and also $\left(\omega_{i}^{I}\right)^{l},\left(\omega_{r}^{O}\right)^{l}$, and $\left(\omega_{d}^{D}\right)^{l}$ are denoted by the terms of variance and covariance of inputs, outputs and intermediate products, respectively calculated as follows:

$$
\begin{array}{ll}
\left(\left(\omega_{1}^{I}\right)^{l}\right)^{2}=\sum_{\substack{j=1 \\
j \neq k}}^{8}\left(\left(\lambda_{j}^{1}\right)^{2} \operatorname{Var}\left(\tilde{x}_{1 j}^{1}\right)^{l}\right)+\left(\lambda_{k}^{1}-\theta\right)^{2} \operatorname{Var}\left(\tilde{x}_{1 k}^{1}\right)^{l}, \quad\left(\left(\omega_{2}^{I}\right)^{l}\right)^{2}=\sum_{\substack{j=1 \\
j \neq k}}^{8}\left(\left(\lambda_{j}^{1}\right)^{2} \operatorname{Var}\left(\tilde{x}_{2 j}^{1}\right)^{l}\right)+\left(\lambda_{k}^{1}-\theta\right)^{2} \operatorname{Var}\left(\tilde{x}_{2 k}^{1}\right)^{l}, \\
\left(\left(\omega_{3}{ }^{l}\right)^{l}\right)^{2}=\sum_{\substack{j=1 \\
j \neq k}}^{8}\left(\left(\lambda_{j}^{1}\right)^{2} \operatorname{Var}\left(\tilde{x}_{3 j}^{1}\right)^{l}\right)+\left(\lambda_{k}^{1}-\theta\right)^{2} \operatorname{Var}\left(\tilde{x}_{3 k}^{1}\right)^{l} ; ; & \left(\left(\omega_{1}^{O}\right)^{l}\right)^{2}=\sum_{\substack{j=1 \\
j \neq k}}^{8}\left(\left(\lambda_{j}^{2}\right)^{2} \operatorname{Var}\left(\tilde{y}_{1 j}^{2}\right)^{l}\right)+\left(\lambda_{k}^{2}-1\right)^{2} \operatorname{Var}\left(\tilde{\mathrm{y}}_{1 k}^{2}\right)^{l},
\end{array}
$$


Non-Parametric Methods for Productivity Analysis of Series Network Production Systems With Stochastic Data

$$
\begin{array}{ll}
\left(\left(\omega_{2}\right)^{l}\right)^{2}=\sum_{\substack{j=1 \\
j \neq k}}^{8}\left(\left(\lambda_{j}^{2}\right)^{2} \operatorname{Var}\left(\tilde{\mathrm{y}}_{2 j}^{2}\right)^{l}\right)+\left(\lambda_{k}^{2}-1\right)^{2} \operatorname{Var}\left(\tilde{\mathrm{y}}_{2 k}^{2}\right)^{l}, & \left(\left(\omega_{3}^{O}\right)^{l}\right)^{2}=\sum_{\substack{j=1 \\
j \neq k}}^{8}\left(\left(\lambda_{j}^{2}\right)^{2} \operatorname{Var}\left(\tilde{\mathrm{y}}_{3 j}^{2}\right)^{l}\right)+\left(\lambda_{k}^{2}-1\right)^{2} \operatorname{Var}\left(\tilde{\mathrm{y}}_{3 k}\right)^{l}, \\
\left(\left(\omega_{1}^{D}\right)^{l}\right)^{2}=\sum_{j=1}^{8}\left(\lambda_{j}^{1}-\lambda_{j}^{2}\right)^{2} \operatorname{Var}\left(\tilde{z}_{1 j}^{1}\right)^{l}, & \left(\left(\omega_{2}^{D}\right)^{l}\right)^{2}=\sum_{j=1}^{8}\left(\lambda_{j}^{1}-\lambda_{j}^{2}\right)^{2} \operatorname{Var}\left(\tilde{z}_{2 j}{ }^{1}\right)^{l}, \\
\left(\left(\omega_{3}{ }^{D}\right)^{l}\right)^{2}=\sum_{j=1}^{8}\left(\lambda_{j}^{1}-\lambda_{j}{ }^{2}\right)^{2} \operatorname{Var}\left(\tilde{z}_{3 j}{ }^{1}\right)^{l}, & \left(\left(\omega_{4}{ }^{D}\right)^{l}\right)^{2}=\sum_{j=1}^{8}\left(\lambda_{j}^{1}-\lambda_{j}^{2}\right)^{2} \operatorname{Var}\left(\tilde{z}_{4 j}{ }^{1}\right)^{l} .
\end{array}
$$

In example 1, the efficiency of the system in periods $t$ and $t+1$ when $\alpha=0.05$ are computed and reported in Table 3. For comparison purposes, MPI evaluations with different confidence interval, taking $\alpha=0.025, \alpha=0.01, \alpha=0.05$ and $\alpha=0.1$ are also examined and presented in Table 3 .

Table 3:The Stochastic MPI for 8 DMUs with different acceptable risk levels.

\begin{tabular}{|c|cccc|c|}
\hline DMUs & $\alpha=0.025$ & $\alpha=0.01$ & $\alpha=0.05$ & $\alpha=0.1$ & Deterministic \\
\hline 1 & 0.949 & 0.819 & 1.025 & 1.208 & 1.046 \\
2 & 1.084 & 1.019 & 1.116 & 1.179 & 1.083 \\
3 & 1.074 & 1.040 & 1.082 & 1.093 & 1.111 \\
4 & 0.994 & 0.933 & 1.024 & 1.166 & 1.171 \\
5 & 0.873 & 0.848 & 0.877 & 1.014 & 1.110 \\
6 & 0.932 & 0.921 & 0.924 & 1.047 & 1.125 \\
7 & 0.926 & 0.904 & 0.932 & 1.010 & 1.163 \\
8 & 1.081 & 1.046 & 1.094 & 1.166 & 1.149 \\
\hline
\end{tabular}

Note that for the simplicity of calculations, the covariance values are set zero in the evaluations of variances for the input/intermediate/output variables and the constraints take the quadratic form. Also, for the case of $\alpha=0.5$, we have $\Phi^{-1}(\alpha)=0$ and it is then achieved similar to that of the deterministic Model (7). According to results in the last column, it can be seen that all DMUs in MPI-deterministic have made a progress in the evaluation. But the results may change by allowing just up to $5 \%$ risk level for the constraints. As the results indicate, DMU4, DMU5, DMU6, and DMU7 are more likely to be located in units with regress status for their performances. On the other side, DMU2, DMU3, and DMU8 show a robust MPI to the provided risks and are located in the progress category. The results of stochastic MPI offers better and more accurate evaluation of productivity status for the production units in this sample.

\subsection{Example 2.An Empirical Application in wheat farming}

In this study, we use a general two-stage model to analyze wheat farming efficiency in provinces of Iran in 2008-2009 crop years. Iran is one of the largest wheat importers in the Middle-East. Wheat farming is important because it provides the main 
Seyedeh S. Hosseini, Reza K. Matin, Zohreh Moghadas, Mohsen Khunsiavash

source of food and the most important agricultural harvests in Iran in terms of production and consumption. Nowadays, wheat is grown in many parts of Iran under irrigation or rained farming, but most of areas in Iran are not under cultivation because of inappropriate soil and water dispensation. Thus, only some parts of the field can be used for natural irrigational agriculture such as the farm lands in Gilan and Mazandaran in northern Iran. On the contrary, some parts of the cultivated lands that are irrigated, for instance in eastern and south eastern Iran such as the lands in Yazd, Sistan-Baluchestanis, and Hormozgan are arid. Azerbaijan, Fars g and Khorasan use winter rains for agriculture.

Figure 2 showsthe wheat farming production process as a network system with four sub-processes. Each sub-processes in the parallel structure is composed of two processes in series structure, i.e., irrigation and rained farming and two series processes in each parallel process: arranging, sowing-growing, and harvesting. Data were gathered from the Iranian Ministry of Agricultural ${ }^{1}$ and the random average of data is shown in Table 4 with approximation on one million.

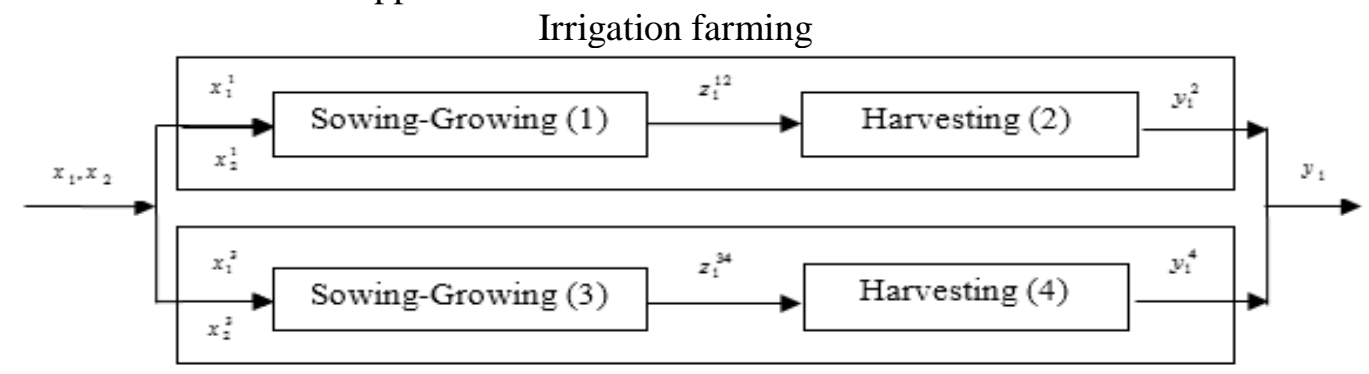

Rained farming

Figure 2: Network structure of provinces for example 2.

In this study, two inputs of the system are cultivated area and consumed seed, respectively. Output is wheat production and the intermediate product in the system is harvested area. In Table 4, 'I' is devoted to irrigation and 'R' shows the rained farming.

Table 4: Random average 31 provinces in period's $t$ and $t+1$ for example 2.

\begin{tabular}{|c|c|c|c|c|c|c|c|c|c|c|c|c|}
\hline \multicolumn{7}{|c|}{ Time period t (2008) } & \multicolumn{6}{|c|}{ Time period t (2009) } \\
\hline & input1 & input2 & $\begin{array}{r}\text { inter } \\
\text { pro }\end{array}$ & $\begin{array}{l}\text { diate } \\
\text { Ict }\end{array}$ & & & input1 & input2 & $\begin{array}{r}\text { inter } \\
\text { pr }\end{array}$ & $\begin{array}{l}\text { diate } \\
\text { ict }\end{array}$ & & \\
\hline 31 provinces & $\mathrm{I}$ & $\mathrm{R}$ & $\mathrm{I}$ & $\mathrm{R}$ & $\mathrm{I}$ & $\mathrm{R}$ & $\mathrm{I}$ & $\mathrm{R}$ & $\mathrm{I}$ & $\mathrm{R}$ & $\mathrm{I}$ & $\mathrm{R}$ \\
\hline $\begin{array}{l}\text { 1.Azerbaijan, } \\
\text { East }\end{array}$ & 0.344 & 0.094 & 0.575 & 2.486 & 0.198 & 0.235 & 4.689 & 2.608 & 0.997 & 0.841 & 0.467 & 2.194 \\
\hline 2.Azerbaijan, & 0.299 & 0.113 & 1.005 & 3.126 & 0.301 & 0.353 & 3.971 & 2.637 & 0.867 & 1.001 & 0.344 & 2.641 \\
\hline
\end{tabular}

${ }^{1}$ www.maj.irhttp://10.7.234.126 
Non-Parametric Methods for Productivity Analysis of Series Network Production Systems With Stochastic Data

\begin{tabular}{|c|c|c|c|c|c|c|c|c|c|c|c|c|}
\hline West & & & & & & & & & & & & \\
\hline 3. Ardabil & 0.196 & 0.09 & 1.161 & 4.531 & 0.227 & 0.426 & 3.861 & 1.795 & 1.215 & 0.616 & 0.469 & 1.107 \\
\hline 4. Isfahan & 0.024 & 0.067 & 0.883 & 3.678 & 0.021 & 0.249 & 0.276 & 2.412 & 0.744 & 1.251 & 0.020 & 3.019 \\
\hline 5. Ilam & 0.066 & 0.043 & 0.757 & 2.907 & 0.050 & 0.127 & 1.490 & 0.773 & 0.944 & 0.643 & 0.140 & 0.498 \\
\hline 6. Bushehr & 0.014 & 0.016 & 0.038 & 2.208 & 0 & 0.036 & 1.148 & 0.489 & 0.305 & 2.027 & 0.035 & 0.993 \\
\hline 7. Tehran & 0.001 & 0.065 & 0.666 & 4.833 & 0 & 0.317 & 0.009 & 1.678 & 0.748 & 1.993 & 0 & 3.347 \\
\hline $\begin{array}{l}\text { 8. Chahar } \\
\text { Mahaal }\end{array}$ & 0.041 & 0.027 & 1.317 & 3.482 & 0.054 & 0.097 & 0.563 & 7.529 & 1.034 & 0.875 & 0.058 & 0.659 \\
\hline $\begin{array}{l}\text { 9. Khorasan, } \\
\text { South } \\
\end{array}$ & 0.019 & 0.040 & 0.339 & 2.526 & 0.006 & 0.101 & 0.218 & 0.800 & 1.067 & 0.643 & 0.023 & 0.515 \\
\hline $\begin{array}{l}\text { 10.Khorasan, } \\
\text { Razavi }\end{array}$ & 0.365 & 0.247 & 0.547 & 3.296 & 0.199 & 0.814 & 3.289 & 6.337 & 0.416 & 0.830 & 0.137 & 5.264 \\
\hline $\begin{array}{l}\text { 11.Khorasan, } \\
\text { North }\end{array}$ & 0.126 & 0.065 & 0.983 & 3.304 & 0.124 & 0.216 & 1.511 & 1.033 & 0.936 & 0.665 & 0.141 & 0.687 \\
\hline 12.Khuzestan & 0.036 & 0.384 & 0.606 & 2.709 & 0.022 & 1 & 2.611 & 8.638 & 0.421 & 1.230 & 0.110 & 11 \\
\hline 13. Zanjan & 0.412 & 0.026 & 0.947 & 3.715 & 0.390 & 0.098 & 3.931 & 1.189 & 1.143 & 1.100 & 0.449 & 1.308 \\
\hline 14. Semnan & 0.007 & 0.030 & 1.588 & 3.464 & 0.012 & 0.104 & 0.226 & 0.799 & 1.281 & 0.994 & 0.028 & 0.795 \\
\hline $\begin{array}{l}\text { 15. Sistan and } \\
\text { Baluchestan } \\
\end{array}$ & 0 & 0.047 & 0 & 2.226 & 0 & 0.105 & 0.024 & 1.733 & 7.617 & 1.220 & 0.018 & 2.114 \\
\hline 16. Fars & 0.108 & 0.350 & 0.727 & 3.369 & 0.079 & 1 & 1.604 & 5.632 & 0.643 & 0.875 & 0.103 & 4.932 \\
\hline 17. Qazvin & 0.060 & 0.052 & 0.828 & 4.052 & 0.050 & 0.213 & 1.117 & 1.630 & 0.769 & 1.678 & 0.086 & 2.736 \\
\hline 18. Qom & 0.001 & 0.008 & 0.710 & 4.329 & 0.001 & 0.036 & 0.027 & 0.470 & 0.543 & 0.621 & 0.001 & 0.292 \\
\hline 19.Kurdistan & 0.512 & 0.037 & 0.872 & 4.000 & 0.447 & 0.149 & 5.650 & 1.020 & 0.933 & 0.901 & 0.527 & 0.920 \\
\hline 20. Kerman & 0 & 0.050 & 2.627 & 3.059 & 0 & 0.154 & 0 & 1.607 & 0.297 & 0.894 & 0 & 1.437 \\
\hline $\begin{array}{l}\text { 21.Kermansha } \\
\text { h }\end{array}$ & 0.347 & 0.078 & 1.038 & 4.790 & 0.360 & 0.375 & 5.676 & 1.289 & 1.191 & 0.803 & 0.676 & 1.035 \\
\hline $\begin{array}{l}\text { 22.Kohgiluyeh } \\
\text { and Boyer }\end{array}$ & 0.074 & 0.026 & 0.819 & 2.675 & 0.060 & 0.070 & 1.197 & 0.374 & 0.967 & 0.509 & 0.115 & 0.190 \\
\hline 23. Golestan & 0.219 & 0.159 & 2.058 & 3.347 & 0.452 & 0.532 & 3.073 & 3.509 & 2.438 & 0.574 & 0.747 & 2.014 \\
\hline 24. Gilan & 0.007 & 0.001 & 1.325 & 2.551 & 0.010 & 0 & 0.265 & 1.805 & 4.176 & 0.387 & 0.110 & 0.700 \\
\hline 25. Lorestan & 0.323 & 0.050 & 0.991 & 2.788 & 0.320 & 0.141 & 4.373 & 1.609 & 1.052 & 0.856 & 0.460 & 1.379 \\
\hline $\begin{array}{l}\text { 26.Mazandara } \\
\text { n }\end{array}$ & 0.038 & 0.012 & 2.606 & 3.695 & 0.101 & 0.047 & 1.895 & 2.484 & 9.455 & 0.553 & 1.792 & 1.374 \\
\hline 27. Markazi & 0.200 & 0.077 & 0.944 & 3.535 & 0.189 & 0.273 & 1.377 & 1.910 & 0.843 & 0.780 & 0.116 & 1.492 \\
\hline 28.Hormozgan & 0 & 0.013 & 0 & 3.689 & 0 & 0.049 & 0 & 0.852 & 0 & 1.699 & 0 & 1.448 \\
\hline 29.Hamadan & 0.350 & 0.097 & 0.867 & 3.907 & 0.304 & 0.382 & 3.570 & 2.432 & 1.226 & 1.266 & 0.438 & 3.080 \\
\hline 30. Yazd & 0 & 0.024 & 0 & 3.282 & 0 & 0.081 & 0 & 0.543 & 0.183 & 1.143 & 0 & 0.621 \\
\hline 31. Kerman & 0 & 0.037 & 0 & 2.315 & 0 & 0.087 & 0 & 1.527 & 0 & 1.565 & 0 & 2.390 \\
\hline
\end{tabular}

Note that the variance of 31 provinces has been gathered in interval $(0.1,1)$. The deterministic DEA model to evaluate the network production system provided in Figure 2 is suggested as follows: 
Seyedeh S. Hosseini, Reza K. Matin, Zohreh Moghadas, Mohsen Khunsiavash

$$
\begin{array}{ll}
\left(E_{k}\right)^{l} & =\min \theta \\
\text { s.t } \quad & \sum_{j=1}^{31}\left(\lambda_{j}{ }^{1}\left(x_{1 j}{ }^{1}\right)^{l}+\lambda_{j}{ }^{3}\left(x_{1 j}{ }^{3}\right)^{l}\right) \leq \theta\left(\left(x_{1 k}{ }^{1}\right)^{l}+\left(x_{1 k}{ }^{3}\right)^{l}\right), \\
& \sum_{j=1}^{31}\left(\lambda_{j}{ }^{1}\left(x_{2 j}{ }^{1}\right)^{l}+\lambda_{j}{ }^{3}\left(x_{2 j}{ }^{3}\right)^{l}\right) \leq \theta\left(\left(x_{2 k}{ }^{1}\right)^{l}+\left(x_{2 k}{ }^{3}\right)^{l}\right), \\
& \sum_{j=1}^{31}\left(\lambda_{j}{ }^{2}\left(y_{1 j}{ }^{2}\right)^{l}+\lambda_{j}{ }^{4}\left(y_{1 j}{ }^{4}\right)^{l}\right) \geq\left(y_{1 k}{ }^{2}\right)^{l}+\left(y_{1 k}{ }^{4}{ }^{l},\right. \\
& \sum_{j=1}^{31}\left(\lambda_{j}{ }^{1}\left(z_{1 j}{ }^{12}\right)^{l}+\lambda_{j}{ }^{3}\left(z_{1 j}{ }^{34}\right)^{l}\right)-\sum_{j=1}^{31}\left(\lambda_{j}{ }^{2}\left(z_{1 j}{ }^{12}\right)^{l}+\lambda_{j}{ }^{4}\left(z_{1 j}{ }^{34}\right)^{l}\right) \geq 0, \\
& \lambda_{j}{ }^{1}, \lambda_{j}{ }^{2}, \lambda_{j}{ }^{3}, \lambda_{j}{ }^{4} \geq 0, \quad j=1, \ldots, 31 .
\end{array}
$$

Here $l \in\{\mathrm{t}, \mathrm{t}+1\}$ shows the two-time periods $\mathrm{t}$ and $\mathrm{t}+1$. In dealing with the stochastic MPI, and after converting the chance-constrained version of Model (9) to its deterministic equivalent model, the following model is achieved to compute the performance of the provinces:

$$
\begin{aligned}
\left(E_{k}\right)^{l}= & \min \theta \\
\text { s.t } \quad & \sum_{j=1}^{31}\left(\lambda_{j}{ }^{1}\left(x_{1 j}{ }^{1}\right)^{l}+\lambda_{j}{ }^{3}\left(x_{1 j}{ }^{3}\right)^{l}\right)-\Phi^{-1}(\alpha)\left(\omega_{1}^{13}\right)^{l} \leq \theta\left(\left(x_{1 k}{ }^{1}\right)^{f}+\left(x_{1 k}{ }^{3}\right)^{f}\right), \\
& \sum_{j=1}^{31}\left(\lambda_{j}{ }^{1}\left(x_{2 j}{ }^{1}\right)^{l}+\lambda_{j}{ }^{3}\left(x_{2 j}{ }^{3}\right)^{l}\right)-\Phi^{-1}(\alpha)\left(\omega_{2}^{13}\right)^{l} \leq \theta\left(\left(x_{2 k}{ }^{1}\right)^{f}+\left(x_{2 k}{ }^{3}\right)^{f}\right), \\
& \sum_{j=1}^{31}\left(\lambda_{j}{ }^{2}\left(y_{1 j}{ }^{2}\right)^{l}+\lambda_{j}{ }^{4}\left(y_{1 j}{ }^{4}\right)^{l}\right)+\Phi^{-1}(\alpha)\left(\left(\omega_{1}{ }^{l}\right)^{l}+\left(\omega_{1}{ }^{l}\right)^{l}\right) \geq\left(y_{1 k}{ }^{2}\right)^{f}+\left(y_{1 k}{ }^{4}\right)^{f}, \\
& \sum_{j=1}^{31}\left(\lambda_{j}{ }^{1}\left(z_{1 j}{ }^{12}\right)^{l}+\lambda_{j}{ }^{3}\left(z_{1 j}{ }^{34}\right)^{l}\right)-\sum_{j=1}^{31}\left(\lambda_{j}{ }^{2}\left(z_{1 j}{ }^{12}\right)^{l}+\lambda_{j}{ }^{4}\left(z_{1 j}{ }^{34}\right)^{l}\right)+\Phi^{-1}(\alpha)\left(\left(\omega_{1}^{12}\right)^{l}+\left(\omega_{1}^{34}\right)^{l}\right) \geq 0, \\
& \lambda_{j}{ }^{1}, \lambda_{j}{ }^{2}, \lambda_{j}{ }^{3}, \lambda_{j}{ }^{4} \geq 0, \quad j=1, \ldots, 31 .
\end{aligned}
$$

Where; 
Non-Parametric Methods for Productivity Analysis of Series Network Production Systems With Stochastic Data

$$
\begin{aligned}
& \left.\left(\left(\omega_{1}^{13}\right)^{l}\right)^{2}=\sum_{\substack{j=1 \\
j \neq k}}^{31}\left(\left(\lambda_{j}^{1}\right)^{2} \operatorname{Var}\left(\tilde{x}_{1 j}^{1}\right)^{l}+\left(\lambda_{j}{ }^{3}\right)^{2}\right) \operatorname{Var}\left(\tilde{x}_{1 j}^{3}\right)^{l}\right)+\left(\lambda_{k}{ }^{1}-\theta\right)^{2} \operatorname{Var}\left(\tilde{x}_{1 k}^{1}\right)^{l}+\left(\lambda_{k}{ }^{3}-\theta\right)^{2} \operatorname{Var}\left(\tilde{x}_{1 k}^{3}\right)^{l}, \\
& \left.\left(\left(\omega_{2}^{13}\right)^{l}\right)^{2}=\sum_{\substack{j=1 \\
j \neq k}}^{31}\left(\left(\lambda_{j}^{1}\right)^{2} \operatorname{Var}\left(\tilde{x}_{2 j}^{1}\right)^{l}+\left(\lambda_{j}^{3}\right)^{2}\right) \operatorname{Var}\left(\tilde{x}_{2 j}^{3}\right)^{l}\right)+\left(\lambda_{k}{ }^{1}-\theta\right)^{2} \operatorname{Var}\left(\tilde{x}_{2 k}^{1}\right)^{l}+\left(\lambda_{k}{ }^{3}-\theta\right)^{2} \operatorname{Var}\left(\tilde{x}_{2 k}^{3}\right)^{l}, \\
& \left(\left(\omega_{1}^{2}\right)^{l}\right)^{2}=\sum_{\substack{j=1 \\
j \neq k}}^{31}\left(\left(\lambda_{j}^{2}\right)^{2} \operatorname{Var}\left(\tilde{\mathrm{y}}_{1 j}^{2}\right)^{l}\right)+\left(\lambda_{k}^{2}-1\right)^{2} \operatorname{Var}\left(\tilde{\mathrm{y}}_{1 k}^{2}\right)^{l}, \quad\left(\left(\omega_{1}^{4}\right)^{l}\right)^{2}=\sum_{\substack{j=1 \\
j \neq k}}^{31}\left(\left(\lambda_{j}^{4}\right)^{2} \operatorname{Var}\left(\tilde{\mathrm{y}}_{1 j}^{4}\right)^{l}\right)+\left(\lambda_{k}^{4}-1\right)^{2} \operatorname{Var}\left(\tilde{\mathrm{y}}_{1 k}^{4}\right)^{l}, \\
& \left(\left(\omega_{1}^{12}\right)^{l}\right)^{2}=\sum_{j=1}^{31}\left(\lambda_{j}^{1}-\lambda_{j}^{2}\right)^{2} \operatorname{Var}\left(\tilde{z}_{1 j}{ }^{12}\right)^{l}, \quad\left(\left(\omega_{1}^{34}\right)^{l}\right)^{2}=\sum_{j=1}^{31}\left(\lambda_{j}^{3}-\lambda_{j}^{4}\right)^{2} \operatorname{Var}\left(\tilde{z}_{1 j}{ }^{34}\right)^{l} .
\end{aligned}
$$

Note that the covariance values are set zero in the above calculations of variances for the input/intermediate/output variables. Table 5represents the results of the estimated stochastic MPI, relation (4), for some different $\alpha$-levels. Also, the deterministic MPI values are included in the last column.

Table 5:Stochastic MPI for 31 provinces with different acceptable risk levels

\begin{tabular}{|l|ccccc|c|}
\hline 31 provinces & $\boldsymbol{\alpha}=\mathbf{0 . 0 0 1}$ & $\boldsymbol{\alpha}=\mathbf{0 . 0 1}$ & $\boldsymbol{\alpha}=\mathbf{0 . 0 5}$ & $\boldsymbol{\alpha}=\mathbf{0 . 1}$ & $\boldsymbol{\alpha}=\mathbf{0 . 4}$ & Deterministic \\
\hline 1. Azerbaijan, East & 6.20 & 6.19 & 6.18 & 6.14 & 6.03 & 5.98 \\
2. Azerbaijan, West & 4.59 & 4.57 & 4.51 & 4.47 & 4.50 & 4.52 \\
3. Ardabil & 2.18 & 2.15 & 2.12 & 2.07 & 2.13 & 2.15 \\
4. Isfahan & 4.86 & 4.85 & 4.84 & 4.80 & 4.81 & 4.82 \\
5. Ilam & 3.05 & 3.03 & 3.01 & 3.00 & 3.05 & 3.05 \\
6. Bushehr & 10.04 & 10.03 & 10.02 & 10.01 & 10.01 & 10.01 \\
7. Tehran & 3.37 & 3.33 & 3.30 & 3.35 & 3.38 & 3.40 \\
8. Chahar Mahaal & 0.438 & 0.440 & 0.441 & 0.444 & 0.450 & 0.451 \\
9. Khorasan, South & 3.75 & 3.78 & 3.80 & 3.83 & 3.85 & 3.88 \\
10. Khorasan, Razavi & 4.65 & 4.63 & 4.61 & 4.59 & 4.56 & 4.53 \\
11. Khorasan, North & 3.20 & 3.17 & 3.13 & 3.09 & 3.00 & 2.96 \\
12. Khuzestan & 4.50 & 4.49 & 4.47 & 4.45 & 4.40 & 4.38 \\
13. Zanjan & 6.47 & 6.46 & 6.46 & 6.46 & 6.45 & 6.44 \\
14. Semnan & 3.49 & 3.51 & 3.52 & 3.54 & 3.58 & 3.60 \\
15. Sistan and Baluchestan & 4.10 & 4.12 & 4.14 & 4.18 & 4.21 & 4.24 \\
16. Fars & 3.40 & 3.59 & 3.57 & 3.55 & 3.53 & 3.47 \\
17. Qazvin & 6.35 & 6.34 & 6.34 & 6.34 & 6.33 & 6.32 \\
18. Qom & 1.90 & 1.91 & 1.93 & 1.95 & 1.98 & 1.99 \\
19. Kurdistan & 6.20 & 6.23 & 6.24 & 6.26 & 6.32 & 6.37 \\
20. Kerman & 2.07 & 2.09 & 2.11 & 2.13 & 2.17 & 2.26 \\
21. Kermanshah & 3.71 & 3.75 & 3.78 & 3.81 & 3.83 & 3.89 \\
22. Kohgiluyeh & 3.15 & 3.19 & 3.21 & 3.24 & 3.26 & 3.27 \\
23. Golestan & 2.52 & 2.50 & 2.48 & 2.43 & 2.41 & 2.39 \\
24. Gilan & 3.11 & 3.09 & 3.07 & 3.03 & 3.00 & 2.97 \\
25. Lorestan & 4.79 & 4.76 & 4.74 & 4.71 & 4.68 & 4.62 \\
\hline
\end{tabular}


Seyedeh S. Hosseini, Reza K. Matin, Zohreh Moghadas, Mohsen Khunsiavash

\begin{tabular}{|l|lllll|l|l|}
\hline 26. Mazandaran & 3.29 & 3.31 & 3.33 & 3.36 & 3.41 & 3.43 \\
27. Markazi & 4.19 & 4.17 & 4.15 & 4.12 & 4.09 & 4.00 \\
28. Hormozgan & 3.65 & 3.69 & 3.71 & 3.73 & 3.74 & 3.76 \\
29. Hamadan & 5.97 & 5.97 & 5.97 & 5.95 & 5.94 & 5.93 \\
30. Yazd & 2.80 & 2.79 & 2.78 & 2.76 & 2.71 & 2.69 \\
31. Kerman south & 5.40 & 5.42 & 5.44 & 5.47 & 5.50 & 5.51 \\
\hline
\end{tabular}

Based on the provided results in deterministic MPI, all the provinces have made a progress except DMU 8. For this unit, all the stochastic-MPI values under all different risk levels are still less than one, which shows that these provinceshave regress in their performances. For the other provinces, the deterministic-MPI is also validated by using different risk levels.

\section{Conclusion}

Nowadays, having information about the regress and progress of systems in their productivity is of prime importance. In conventional deterministic view of productivity analysis, a traditional DEA evaluation is conducted for deterministic and known prices. However, as many production and process planning decisions are made in anticipation of unknown and stochastic information, the evaluation itself introduces a bias with unknown properties. In this paper, in addition to considering the stochastic data, which in most production systems helps get close to analyzing the real environment, the regress and progress of productivity was investigated. In recent years, Malmquist productivity index has attracted a considerable attention in DEA evaluation of network production systems, but these studies did not address the MPI evaluation for series network systems. To do so, a novel Network-DEA based MPI approach was introduced in this study for dealing with stochastic data. The associated deterministic equivalent model in quadratic form was then introduced to alleviate the computational burden of the required optimization models. Acquiring the results of this approach makes it possible to enhance the productivity evaluation of the systems. It is assumed that the inputs/intermediate products/outputs data follow a normal distribution, which is a common assumption in collecting data. Finally, with two numerical examples, it was shown that to provide a more realistic productivity evaluation, the deterministic MPI evaluation needs to be reexamined with stochastic MPI if the data are available in stochastic form. As a future effort, a study is suggested to investigate whether other types of statistical distributions could be used instead of normal distribution, for example, the skewed or truncated normally distributed data. 
Non-Parametric Methods for Productivity Analysis of Series Network Production Systems With Stochastic Data

\section{REFERENCES}

[1]Aparicio, J., Crespo-Cebada, E., Pedraja-Chaparro, F. and Santín D. (2017),Comparing School Ownership Performance Using a Pseudo-Panel Database: A Malmquist-type Index Approach. European JournalOperation Research, 256(1), 533-542;

[2] Charnes, A., Cooper, W.W. and Rhodes, E. (1987), Measuring the Efficiency of Decision Making Units. European Journal Operation Research, 2(2), 429-444;

[3] Chen, Y. and Zhu, J. (2004), Measuring Information Technology's Indirect Impact on Firm Performance. Springer, 5(2), 9-22;

[4] Cooper, W.W., Deng, H., Huang, Z. and Li, S.X. (2004), Chance Constrained Programming Approaches to Congestion in Stochastic Data Envelopment Analysis. European Journal Operation Research, 155(1), 487-501;

[5] Färe, R. and Grosskopf, S. (2000), Network DEA. Soc. Econ. Plan. Science, 34(2), 35-49;

[6] Farrell, M.J.(1957), The Measurement of Productive Efficiency. J. Royal Stat. Society, 120(3), 253-282;

[7] HosseinzadehLotfi, F., Jahanshahloo, G.R., Behzadi, M.H., Mirbolouki, M. (2011), Estimating Stochastic Malmquist Productivity Index. World Apply Science, 13(1), 2178-2185;

[8] Kao, C. and Hwang, S.N. (2008), Efficiency Decomposition in Two-Stage Data Envelopment Analysis: An Application to Non-life Insurance Companies in Taiwan. European Journal Operation Research, 85(2), 418-429;

[9] Kao, C. (2009), Efficiency Decomposition in Network Data Envelopment Analysis: a Relational Model. European Journal Operation Research, 192(3), 949962;

[10] Kao, C. and Hwang, S.N. (2010), Efficiency Measurement for Network Systems: IT Impact on Firm Performance. Operation Research, 48(2), 437-446; [11] Kao, C. and Hwang, S.N. (2011), Decomposition of Technical and Scale Efficiencies in Two-Stage Production Systems. European Journal Operation Research, 211(1), 515-519;

[12] Kao, C. (2014), Efficiency Decomposition in Network Data Envelopment Analysis with Slacks-based Measures. Omega, 45(1), 1-6;

[13] Kao, C. (2014), Efficiency Decomposition for General Multi-Stage Systems in Data Envelopment Analysis. European Journal Operation Research, 232(3), 117-224; [14] Kao, C. and Hwang, S.N. (2014), Multi-period Efficiency and Malmquist Productivity Index in Two-Stage Production Systems. European Journal Operation Research, 232(2), 512-521; 
Seyedeh S. Hosseini, Reza K. Matin, Zohreh Moghadas, Mohsen Khunsiavash

[15] Kao, C. (2016), Malmquist Productivity Index for Network Production Systems. Omega, 40, 10-16;

[16] Kao, C. (2017), Measurement and Decomposition of the Malmquist

Productivity Index for Parallel Production Systems. Omega, 67, 54-59;

[17] KazemiMatin, R. and Azizi, R. (2015), A Unified Network-DEA Model for

Performance Measurement of Production Systems. Measurement, 60(1),186-193;

[18] Khodabakhshi, M., Jahanshahloo, G.R., HosseinzadehLotfi, F. and

Khoveyni, M. (2012), Estimating Most Productive Scale Size with Imprecise-Chance Constrained Input-Output Orientation Model in Data Envelopment Analysis. Computer Ind Eng, 63(1),254-261;

[19] Kuosmanen, T. (2006), Stochastic Nonparametric Envelopment of Data: Combining Virtues of SFA and DEA in a Unified Framework. MTT Discussion Paper, 50-58;

[20] Lozano, S. (2011), Scale and Cost Efficiency Analysis of Networks of Processes. Expert Syst, 38(3), 6612-6617;

[21] Maniadakis, N. and Thanassoulis, E.(2004), A Cost Malmquist Productivity Index. European Journal Operation Research, 154(1), 396-409;

[22] Ross, A., Kuzu, K. and Li, W. (2016), Exploring Supplier Performance Risk and the Buyer's Role Using Chance-Constrained Data Envelopment Analysis.

European Journal Operation Research, 250(2), 966-978;

[23] Yao, X., Guo, C., Shao, Sh. and Jiang, Z.(2016), Total-factor $\mathrm{CO}_{2}$ Emission

Performance of China's Provincial Industrial Sector: a Meta-frontier Non-radial Malmquist Index Approach.Energy, 184(4), 1142-1153. 